\title{
La información, un recurso en alza: El futuro de la documentación en los museos
}

\author{
Information, a Resource on the Rise: \\ The Future of Documentation in Museums
}

\author{
Ana Ma Martín Bravo \\ Museo Nacional del Prado \\ C/ Ruiz de Alarcón, 23, 28014 Madrid \\ ana.martin@museodelprado.es
}

Recibido: 11-04-2014

Aceptado: 1-06-2014

\begin{abstract}
RESUMEN
La información es un recurso trascendental en las economías actuales y los museos empiezan a darse cuenta de la importancia de difundir el conocimiento de sus colecciones a través del potente canal de comunicación que es la web. El saber acumulado por años de investigación, trasmitido mediante publicaciones en papel, empieza a fluir a través de la red, acercando al museo a los miles de usuarios que no van a poder visitarlo físicamente. El desprendimiento generoso de esa información tiene su lógica en el modelo del "potlatch digital", en el que la visibilidad de la información hace aumentar su valor y proporciona prestigio a la institución que la ha puesto en circulación sin restricciones. El futuro de los servicios documentales de los museos, incluidas las bibliotecas y los archivos, está en facilitar esa apertura, pensar y trabajar para la comunidad global, obteniendo asi su reconocimiento.
\end{abstract}

Palabras Clave: Documentación. Museos. Libre acceso a la información. "Potlatch digital".

\begin{abstract}
Information is a vital resource in the current economic climate and thus museums have begun to realise the importance of raising awareness of their collections through the powerful communication channel that is the World Wide Web. The acquired knowledge of years of research, erstwhile transmitted through printed matter, now begins to flow through the net, bringing museums closer to the thousands of users who would otherwise be unable to visit them in person. The generous sharing of this information finds its inspiration in the "digital potlatch" model, whereby the free availability of the said information increases its value and earns prestige for the institution that authorised its unrestricted circulation. The future of documentary services in museums-libraries and archives included-lies in facilitating that openness, as well as in considering and working for the global community, thereby attaining its recognition.
\end{abstract}

KEY WORDS: Documentation. Museums. Free access to information. "Digital potlatch". 


\section{Introducción}

Al plantearnos la cuestión de cómo las nuevas tecnologías están afectando a la museología y de cómo la globalización ha propiciado nuevas dinámicas en el mundo de los museos, el Departamento de Prehistoria me brinda la ocasión de recuperar modelos teóricos aprendidos en mis años de alumna aquí y aprovecharlos para explicar comportamientos relacionados con el ámbito de la documentación en museos, campo al que me dedico actualmente ${ }^{1}$. Nada más gratificante que esta oportunidad de explicar por qué la información se ha convertido en un recurso en alza, en un bien preciado que los museos poseen sobre sus colecciones, volviendo sobre todo lo aprendido sobre el potlatch en mis cursos de doctorado y luego aplicado a mis investigaciones sobre finales de la Edad del Bronce y la del Hierro.

En aquellos años conocí el significado de desprenderse de riqueza en algunas sociedades del Bronce Final; de cómo determinados individuos poseedores de bienes que son especialmente apreciados por la comunidad, dejan de atesorar esa riqueza para sí y, a la vista de todos, celebran rituales en los que derrochan esos bienes, perdiendo la propiedad, pero ganando un prestigio que los sitúa como líderes del grupo (Ruiz-Gálvez 1995: 131 y 1998: 35). El interesante trabajo sobre $\mathrm{El}$ potlatch digital, de Ortega y Rodríguez (2011), me ha hecho volver sobre esos planteamientos, que me van a permitir abordar en estas páginas el fenómeno de la distribución del conocimiento a través de Internet, para reflexionar sobre cómo la información sobre las colecciones de los museos puede ser en estos momentos ese bien apreciado por la comunidad, celosamente guardado por las instituciones hasta fechas recientes, que algunos museos están empezando a hacer accesible a través de sus páginas web con un rigor y una calidad idéntica a la de las publicaciones impresas en papel $y$, al ofrecer esa riqueza de manera gratuita, sin restricciones, la comunidad les otorga un reconocimiento social que los sitúa como instituciones de prestigio, siendo un referente para el resto de los museos.

\section{La Información como recurso}

F. Hernández titulaba uno de sus trabajos $E l m u$ seo como espacio de comunicación (1998) y es cierto que los profesionales que trabajamos en el ámbito de los museos somos conscientes de la importancia de saber comunicarse con el público. Lo que ha variado a lo largo del tiempo ha sido la forma de establecer esa comunicación. Los cambios de la sociedad han obligado a la museología a desarrollar nuevos planteamientos teóricos $\mathrm{y}$, a las instituciones, a adaptarse a esos cambios para asegurar su propia subsistencia. El sistema de comunicación globalizada que tenemos al alcance a través de Internet ha sacudido a los museos hasta el punto de que podamos plantear la existencia de "museos sin objetos materiales, porque es la misma virtualidad la que los reconstruye y les da vida en la imagen que los ilustra, interpreta y expone en una pantalla" (Hernández 2006: 263). Ante esto, se ha producido una reacción interesante, los museos están queriendo mostrar sus colecciones a través de estos nuevos cauces de comunicación, estrechándose el vínculo entre lo real y lo virtual. Surgieron así los primeros intentos de mostrar la colección en Internet a través de las páginas webs de las instituciones, pero con un enfoque basado en mostrar sólo una parte de la colección, los objetos destacados, lo más significativo. Detrás de esta forma de actuar subyace la concepción que el museo tenía de la web como una herramienta de ocio cultural, que utiliza para atraer a los visitantes, para facilitarles su experiencia en el museo: "Nosotros te comunicamos qué exposiciones tenemos y tú miras nuestros horarios o cómo venir a vernos", éste es aún el mensaje de muchas de las web de museos, lamenta Maxwell L. Anderson (2010: 140), después de tantos años de desarrollo de la red. El modelo teórico que sustenta esta forma de actuar es el que concibe la información que se da a través de la web como un producto para el turismo de masas, una réplica de los folletos guías en papel, muy lejos de considerar la web un canal apropiado para difundir conocimiento científico. Sin embargo, en estos momentos, estamos asistiendo a un cambio profundo, los museos dan un nuevo enfoque a la información que se ofrece a través de su página web y surgen voces que invitan a los museos a que "se liberen de los prejuicios y del sistema de valores que han recibido en herencia" y asuman entre sus competencias los nuevos medios de comunicación (Deloche 2002: 189). Cada vez más lejos de esa concepción de producto de ocio, la información que se muestra en la web está pasando a ser un recurso en sí mismo, compitiendo con los libros en papel como canal para hacer pública la información y las investigaciones sobre las colecciones. Están haciendo su aparición en la web los catálogos colectivos de los museos, igual de 
rigurosos que los que tradicionalmente se ofrecía en cuidadas publicaciones pensadas sólo para unos pocos. Curiosamente, los museos que han empezado este camino son aquellos que han querido mantener su prestigio como institución museística relevante, estar bien posicionados en el ranking de los que profesionales y visitantes consideran mejores. ¿Qué está pasando para que esto suceda? Varios fenómenos han confluido, porque un cambio de esta naturaleza implica un enorme esfuerzo para las instituciones, supone tener que revisar la información que ofrecen, ahora expuesta a la comunidad global de usuarios de Internet. Pero, sobre todo, deben superar los prejuicios internos que todavía mantienen muchos de los profesionales de los museos, apegados al concepto de que la información de calidad debe ser accesible sólo para una minoría de expertos en la materia. "Si exceptuamos la colección, el principal recurso de la institución es la información, y ese otro núcleo de negocio está aún sin explotar. La información es la clave para la economía moderna" señalaba A. Gutiérrez (2010: 32). Esta afirmación ya presagiaba el camino que presumiblemente tendrían que iniciar los museos.

Creo que, entre las circunstancias que han permitido el cambio de mentalidad, podemos señalar el hecho de que las exposiciones temporales han dejado de ser el reclamo que utilizaban los museos para comunicarse con el público. Desde mediados de los años 90 y durante la primera década de este siglo, los museos grandes y pequeños han puesto el centro de su interés en estas exposiciones, que han acaparado buena parte de sus recursos económicos y humanos para la gestión de los préstamos de obras y el montaje de salas dedicadas ex profeso a este fin, que se renovaban de manera constante. Hoy día se asiste a un descenso muy importante de los recursos que se pueden dedicar a estos eventos, cada vez de un coste mayor dado el incremento de los gastos en seguros, medios de transporte y todo lo relacionado con el diseño. Ha llegado el momento de que las exposiciones temporales dejen de sucederse a un ritmo de vértigo y los museos vuelvan los ojos a la colección. La ecuación menos recursos para eventos efímeros, más demanda de información por parte de la sociedad y más interés por lo no efímero (la colección estable) está teniendo como resultado el cambio. Aún es pronto para saber si estamos en lo cierto, pero si se consolida la tendencia de que la exposición temporal, concebida como evento, deje de ser el principal medio de comunicación entre el museo y el público, sus páginas web pronto reflejarán el cambio de paradigma. Ahora, estamos habituados a tener a las exposiciones como centro de la atención de la web de los museos, teniendo el acceso a la colección como una sección secundaria de la página; es previsible que ese centro lo acapare la información sobre la colección, a medida que los museos vayan siendo conscientes de que ese es su valor más cotizado.

\section{El modelo del Potlatch Digital}

Otra de las claves que explican por qué algunos museos han puesto sus catálogos en línea en los últimos tiempos la encontramos en el trabajo de Ortega y Rodríguez (2011) sobre el potlatch digital, donde estudian el fenómeno de la Wikipedia y el triunfo del conocimiento compartido, propiciando un modelo que tiene una interesante aplicación en el mundo de los museos.

Estos autores exponen su teoría con acierto y gran agudeza, partiendo de la base de que "en Internet se entrega, difunde y dispensa conocimiento gratuito, porque ser desinteresado genera interés y porque a cambio de contenidos tangibles puede obtenerse reconocimiento y lustre intangible" (Ibíd:: 26). Los defensores de los actuales sistemas de difusión del conocimiento, siempre a través de los cauces de las publicaciones en papel de carácter científico, encuentran absolutamente incomprensible que los museos utilicen este nuevo canal de información que proporciona la web para ofrecer de manera desinteresada y abierta los últimos avances de sus investigaciones. Si todavía hay muchos de los que trabajan en estas instituciones que se resisten a ofrecer una apertura a través de la red al conocimiento completo de la colección, ofreciendo la misma calidad en los contenidos que ofrecen los libros impresos, es posible que la lectura del potlatch digital les hiciera cambiar y entendieran por qué museos como el British Museum facilita de manera altruista información e imagen de casi la totalidad de las obras que forman su colección.

¿Pierden las instituciones ingresos por la pérdida de ventas de los libros en papel o las imágenes? No lo creemos, no es ese un argumento sólido. Al contrario, existe un beneficio para la institución, que puede no ser económico. La contribución desprendida del patrimonio del conocimiento no es sinónimo de ausencia de crédito, ya que el desprendimiento inicial se compensa con el reconocimiento que la institución alcanza en 
la sociedad, nos explican Ortega y Rodríguez (2011: 183), porque "el prestigio, según la lógica del potlatch digital, proviene de la exposición pública y el incremento de la visibilidad". Es necesario mostrarse sin reservas para obtener el reconocimiento de la comunidad (p.120), que en el caso de los museos va a estar constituida no sólo por los visitantes reales sino por todos los que nunca tendrán la posibilidad de entrar físicamente en el museo. El capital que obtienen las instituciones museísticas es el de ganar renombre y prestigio ante un enorme colectivo, que supera en cifras al número de los visitantes físicos. A la postre, las instituciones que acaparan el prestigio pueden transformar ese capital simbólico en otro tipo de crédito, pensemos en lo útil que puede ser para la búsqueda de patrocinio.

En el modelo original del potlatch de los indios kwakiutl de Canadá, el desprendimiento voluntario de la riqueza por parte de algunos les confería el reconocimiento de la tribu y la categoría de jefe (Ortega y Rodríguez 2011: 36). Ese mismo modelo aplicaba Marisa Ruiz-Gálvez para entender el depósito de más de cuatrocientas piezas de bronce, en su mayoría armas, en la Ría de Huelva durante los últimos momentos del Bronce Final. "Esa amortización de riqueza en actos públicos constituye un potlatch, una exhibición de riqueza y poder por parte de un individuo, una familia o un linaje. Es un acto de propaganda política, pero también tiene un aspecto económico" (RuizGálvez 1995:131). En el caso de los museos, con esa entrega generosa de información a través de la red, que antes era un bien restringido al ámbito de los especialistas, lo que consiguen es destacar sobre el resto de instituciones de su misma categoría, como estamos viendo que ha sucedido en el caso de museos como el Metropolitan de Nueva York o el British Museum, y están generando una corriente a la que se suman todos aquellos que quieren obtener ese mismo reconocimiento.

Esta tendencia no es un hecho aislado, forma parte del movimiento generalizado de intercambio de información en Internet, posible por el desarrollo de los protocolos del Linked Open Data, los datos de libre acceso y la filosofía de la web semántica ${ }^{2}$. La gran repercusión que está teniendo en el mundo de las bibliotecas y las universidades la libre distribución de contenidos científicos ha preparado el camino para que la comunidad advierta los beneficios que proporciona dar y recuperar información vía Internet. Según el modelo del potlatch digital, el que más da, más prestigio acumula y los museos, que de alguna manera han ido siendo conscientes de ello, han querido participar de este movimiento poniendo información relevante sobre todos sus fondos accesible a la comunidad de usuarios de la web, siempre muy superior en número a la de visitantes reales del museo o de lectores de sus catálogos en papel (Anderson 2010: 144).

Para superar las reticencias de los profesionales del museo a trabajar en esta vía, hay que buscar la manera de que éstos no vean en la libre circulación de datos un atentado contra sus derechos a ser reconocidos como autores de un trabajo científico. La solución que hemos adoptado en el Servicio de Documentación del Museo del Prado es la de poner la fuente de donde proceden los datos de catalogación y comentarios sobre la obras de arte, terminando las fichas web de la Galería online indicando de dónde se ha extractado el texto informativo. Las secciones de investigación, por otra parte, permiten difundir a través de la red estudios con el formato similar al de una publicación en papel, con las ventajas que le proporciona la red de gratuidad e inmediatez. En esta línea se encauza la labor que realiza el Departamento de Dibujos y Estampas del Museo del Prado, que en las últimas exposiciones temporales ha optado por no imprimir en papel el catálogo de la exposición, sino ponerlo en la web para todos los usuarios (Matilla 2011, 2013). Se distribuye un recurso digital, maquetado con idéntico formato que un catálogo impreso, pero enriquecido con interesantes vínculos a otras páginas web, que añade a las citas bibliográficas un link al texto citado, lo que abre la posibilidad de interaccionar con otros recursos digitales. Este reparto gratuito del catálogo está al alcance sólo de unas pocas instituciones que pueden permitirse este tipo de distribución generosa de sus investigaciones más apreciadas, como son los catálogos de las exposiciones. Sin embargo, el gesto desinteresado se ve recompensado con algún beneficio en el orden material. De hecho, el éxito conseguido con el proyecto No sólo Goya (Matilla 2011), pensamos que propició un reconocimiento a este tipo de actuaciones que facilitó que el siguiente proyecto (Matilla 2013) contara con nuevos patrocinadores vinculados al ámbito digital.

El mundo global de usuarios que no tiene la posibilidad de desplazarse físicamente hasta el museo está demandando a los museos ir en esa dirección. Ahora tenemos la oportunidad de responder a ese reto. 


\section{El Futuro de los Servicios Documentales de los Museos}

La información que se muestra en la página web sobre la colección de un museo tiene que ser dinámica, requiere una actualización constante, para no defraudar las expectativas de los usuarios, esa es la clave del reconocimiento que se persigue. Para que eso sea posible, tiene que estar respaldada por programas de gestión y documentación de las colecciones que permitan alimentarla de manera continua. En definitiva, tener un catálogo de la colección en línea necesita establecer un flujo constante de información entre la base de datos interna de colecciones y la web. El papel de los servicios de documentación de los museos es vital en este proceso, que de ahora en adelante añaden a su papel de gestores de la información sobre los objetos del museo, el de ser proveedores de contenidos de la web de la institución. En este modelo, la base de datos interna de obras de arte y el catálogo online son dos caras de la misma moneda y, cuanto más se aproximen las dos, mayor será el éxito del proyecto (Martín Bravo y Pantoja e. p.).

En el Museo del Prado hemos trabajado durante los últimos años con la máxima de que la información que surge de la gestión de las obras de arte se convierta en un dato de manera inmediata. Movimientos, préstamos a exposiciones y restauraciones son labores que se realizan a diario en los museos y que constituyen la historia de las obras. Si pretendemos que toda esa información, que interesa tanto a usuarios internos como externos, esté actualizada en tiempo real, se necesita contar con programas que transformen los procesos de trabajo de los diferentes departamentos de la institución en datos, sin tener que procesarlos desde el Servicio de Documentación. Para ello, se ha creado un sistema integrado de documentación, en el que trabajan las diferentes áreas del museo, consensuando qué parte de los datos que se gestionan desde el sistema son visibles en la consulta de colecciones. De esta manera, la alimentación de la consulta es automática en campos como ubicación, participación en exposiciones, restauraciones, análisis y estudios técnicos, cartelas, marcos o imágenes de la obra. La experiencia de cualquiera de los que trabajamos en museos nos dice que es indispensable la integración con los departamentos de gestión si pretendemos evitar que la base de datos de la colección esté desfasada.

Otra vía que se ha seguido para enriquecer la consulta de colecciones ha sido la de crear vínculos con otras bases de datos del museo, que no están relacionadas con la gestión, pero sí ofrecen datos imprescindibles sobre los objetos, como son la de biblioteca y la del archivo del museo. Se diseñó un sistema que permite recuperar, desde cada ficha de una obra de arte, tanto los registros bibliográficos como los documentos de archivo especialmente vinculados con ella. De esta forma, se recuperan las catalogaciones que bibliotecarios $\mathrm{y}$ archiveros del museo realizan, que se visualizan desde la consulta de cada una de las obras de arte. Esta vinculación de la bibliografía específica de cada obra o sus documentos de ingreso ya digitalizados facilita muchísimo la tarea de los usuarios, pero además, ha demostrado ser muy eficaz para hacer sostenible la biblioteca con el menor número posible de personal auxiliar, con la combinación de referencias bibliográficas seleccionas, libre acceso a los libros y evitando el préstamo de documentos originales.

Desde 2009, el Servicio de Documentación del Museo del Prado forma parte del Área de Biblioteca, Archivo y Documentación, permitiendo que estos tres pies de los servicios documentales resuelvan de manera eficaz la integración de servicios y funciones que se prestan en la Sala de Lectura de la biblioteca del museo y facilita el flujo de la información (Docampo y Martín Bravo 2009). El Área es la encargada de elaborar el modelo de consulta de colecciones y de transmitirlo a los técnicos informáticos del museo, que desarrollan programas a medida de las necesidades que se van planteando, lo que permite una actualización permanente de las prestaciones de la base de datos. Documentación también tiene la misión de alimentar la Galería online hasta cumplir con el objetivo marcado en el plan estratégico 2013-2016 de hacer accesible a través de la web la totalidad de la colección (Museo del Prado 2013: 37).

Más allá de cumplir con los objetivos de recopilación y procesado de la información, para hacerla accesible a usuarios internos y externos del museo, el futuro de los servicios documentales tiene que contemplar ampliar su horizonte. J. Docampo (2013: 198) señalaba que si los museos están abiertos a todos, sus bibliotecas y archivos también deben estarlo, emprendiendo el mismo camino de visibilidad a través de la web que están siguiendo las colecciones. Además, auguraba un futuro prometedor especialmente a los archivos de museos, poco conocidos, cuyo descubrimiento va a permitir "reescribir algunos capítulos de la historia cultural insuficientemente estudiados".

Las bibliotecas y archivos de museos deberán también mostrar sus recursos a la comunidad de 
usuarios de la web, mucho más amplia que el número de investigadores especializados que acuden a diario a ellos. El esfuerzo que supone digitalizar sus registros estará más justificado si se aprovecha este canal de difusión del conocimiento que está siendo Internet para ponerlo en circulación, repercutiendo las inversiones en un mayor número de usuarios y obteniendo la institución reconocimiento por parte de la sociedad, siempre ateniéndose a los límites que marcan la ley de la propiedad intelectual y la de protección de datos.

La integración de estos servicios documentales en una misma área facilitará trazar un único camino hacia la normalización y la utilización de estándares comunes, vía imprescindible para mostrar los recursos de la mejor manera para ser reconocidos por los buscadores. En esto, la convergencia de servicios documentales debe estar encaminada a que todas las áreas de un museo utilicen los mismos vocabularios, evitando situaciones que han sido habituales en la mayoría de nuestras instituciones, como el que las listas de autoridades no sean comunes para las bases de datos de la colección, de la biblioteca o del archivo. $\mathrm{Si}$ queremos compartir nuestros recursos con los usuarios externos, si pretendemos hacerlos accesibles a través de los programas de búsqueda, tenemos que comenzar por aplicar una normalización que afecte a todos los servicios implicados en la documentación, evitando que cada cual siga unas pautas diferentes. Aunque lo que falta por hacer aún es mucho, sólo conseguiremos el objetivo si nos trazamos esa meta.

\section{Conclusiones}

Un nuevo público ha hecho su aparición en el mundo de los museos, aquel que los visita a través de la página web de la institución. Miles de personas que no van a venir al edificio del museo sí van a entrar, en cambio, a conocer su colección a través de Internet. Esta aparición de nuevos visitantes ha provocado que los museos estén cambiando la forma de comunicarse con ellos. Asistimos a un desplazamiento de las exposiciones temporales como medio de atraer la atención de los usuarios en favor de la información que da de sus colecciones, de su investigación.

La representación de la obra de arte y su información es más que nunca un recurso en alza. Hasta ahora, esa información ha sido un bien que los museos guardaban en dossiers en papel, que fluía por el cauce de las publicaciones científicas entre un reducido número de especialistas. En estos momentos, la sociedad demanda imágenes e información de manera masiva; el museo debe ser consciente de que posee un bien apreciado por la comunidad, no por una minoría. Si se guarda esa riqueza para sí, difundiéndola como hasta ahora, se queda al margen del movimiento generalizado de libre intercambio de información impulsado por los desarrollos del Linked Open Data y la web semántica. Sabiamente, algunos museos ofrecen ya de manera gratuita una enorme riqueza de datos sobre todos sus fondos, incluyendo la imagen, en un gesto generoso y sin precedentes de desprendimiento altruista del conocimiento acumulado durante años de trabajo. A cambio, esas instituciones están obteniendo con esa forma de actuar un reconocimiento social que los sitúa como líderes indiscutibles en el campo de la cultura, con tanto predicamento, que son verdaderos iconos de nuestro mundo. El fenómeno es comprensible bajo el paradigma del potlatch digital de Ortega y Rodríguez (2011), según el cual el desprendimiento es el principio fundamental de la adquisición de rango. No olvidemos que el prestigio que se alcanza, se traduce la mayoría de las veces en otro tipo de riqueza que compensan esa pérdida inicial.

El canal de difusión es la página web del museo, que ha dejado de ser una web folleto para convertirse en un fin, un destino al que se quiere llegar, no un medio para facilitar la visita al museo. Los servicios de documentación somos los proveedores de contenidos de la web de la institución $\mathrm{y}$, además, los profesionales que tenemos que preparar los cauces para difundir la información a través de la red. A nosotros nos corresponde desarrollar el modelo de gestión y difusión de información de las obras de arte, transmitirlo a los técnicos en informática y a los servicios web para que ellos construyan las vías de salida desde las bases de datos internas a la consulta online. Es imprescindible normalizar según estándares internacionales y ello sólo se hará si nuestro objetivo es llegar a los miles de usuarios que nunca visitarán nuestro centro físicamente, pero sí su página web.

El profesional de la documentación en museos debe asumir el compromiso de transformar la riqueza potencial que es la información sobre los objetos en recursos que lleguen al mayor número de usuarios, mostrar sin temor, buscar el equilibrio entre la difusión y la calidad de los contenidos, para que el museo consiga ser un sitio web destacado y obtener el reconocimiento de la comunidad global. 


\section{Notas}

1. Mi agradecimiento a F. Hernández por iniciarme en la museología. Al invitarme a participar en este número de Complutum me ha dado la ocasión de aunar mi formación en Prehistoria con el mundo de los museos, en lo que ella es para mí un ejemplo a seguir. Mi gratitud también al resto de profesores del Dto. de Prehistoria con los que me doctoré, M. Almagro, A. Jimeno, M. Ruiz-Gálvez y G. Ruiz Zapatero, porque la sólida formación que me trasmitieron está en la base de mi trayectoria profesional.

2. Más información sobre la web semántica en [URL: http://www.w3c.es/Divulgacion/GuiasBreves/WebSemantica]. Acceso el 13/03/2014.

\section{REFERENCIAS Bibliográficas}

Anderson, M. L. (2010): El Museo y las nuevas tecnologías. El Museo: hoy y mañana (Ph. Montebello, ed.), Museo Nacional del Prado. Madrid: 139-158.

Deloche, B. (2002): El museo virtual. Hacia una ética de las nuevas imágenes. Trea, Gijón.

Docampo, J. (2013): Poetas en tiempos de miseria. Límites y retos de los servicios documentales de museos. El profesional de la información, mayo-junio, vol. 22: 197-202 [URL: http://www.elprofesionaldelainformacion.com/contenidos/2013/mayo/01.pdf]. Acceso el 10/03/2014.

Docampo, J.; Martín Bravo, A. Ma (2009): El Área de Biblioteca, Archivo y Documentación del Museo Nacional del Prado: Hacia una integración de procesos y servicios. XI Jornadas de Gestión de la Información. Servicios polivalentes, confluencia entre profesionales de archivo, biblioteca y documentación. SEDIC: 53-65.

Gutiérrez Usillos, A.; Martín Bravo, A. Maa; Martínez Pozuelo, F.; San Juan, C. (2009): La aplicación de las nuevas tecnologías de gestión y consulta documental en el Museo del Prado durante el plan 20052008. Revista de Museología, 45: 22-32.

Gutiérrez Usillos, A. (2010): Museología y documentación. Criterios para la definición de un proyecto de documentación en museos. Trea, Gijón.

Hernández Hernández, F. (1998): El museo como espacio de comunicación. Trea, Gijón.

Hernández Hernández, F (2006): Planteamientos teóricos de la museología. Trea, Gijón.

Martín Bravo, A. Ma ; PANtoja, J. (e.p.): Integración de servicios documentales: el nuevo website del Museo del Prado. II Jornadas de Bibliotecas de Museos. MNP, Ministerio de Cultura, Educación y Deporte.

Matilla, J. M. (2011): No sólo Goya: adquisiciones para el Gabinete de Dibujos y Estampas del Museo del Prado, 1997 - 2010. Museo Nacional del Prado. [URL: https://www.museodelprado.es/exposiciones/ info/en-el-museo/imagenes-en-papel/la-exposicion/catalogo/]. Acceso el 4/03/2014.

Matilla, J. M. (2013): Roma en el bolsillo: cuadernos de dibujo y aprendizaje artístico en el siglo XVIII. Museo Nacional del Prado. [URL: https://www.museodelprado.es/exposiciones/info/en-el-museo/romaen-el-bolsillo-cuadernos-de-dibujo-y-aprendizaje-artistico-en-el-siglo-xviii/catalogo-online/]. Acceso el $5 / 03 / 2014$.

Museo Nacional del Prado (2013): Plan de Actuación 2013-2016 [URL: https://www.museodelprado.es/ uploads/media/Plan_2013-2016.pdf]. Acceso el 13/03/2014.

Ortega, F.; Rodríguez, J. (2011): El potlatch digital. Wikipedia y el triunfo del procomún y el conocimiento compartido. Cátedra, Madrid.

Ruiz-Gálvez Priego, M. (ed.) (1995): Ritos de Paso y puntos de paso. La Ría de Huelva en el mundo del Bronce Final Europeo. Complutum, Extra 5. Universidad Complutense de Madrid.

Ruiz-Gálvez Priego, M. (1998): La Europa Atlántico en la Edad del Bronce. Un viaje a las raíces de la Europa continental. Crítica/Arqueología, Barcelona. 